\title{
Knowledge and practices in the use of antibiotics among a group of Nigerian university students
}

\author{
Igbeneghu Oluwatoyin Abimbola \\ Department of Pharmaceutics, Obafemi Awolowo University, Ile-Ife, Nigeria
}

doi: 10.3396/ijic.v9i1.007.13

\begin{abstract}
The study examined the knowledge and practice of antibiotic use among students in a university in south western Nigeria. A questionnaire was administered to each of 500 students drawn from all the Departments in the university excluding those from the faculty of Pharmacy, Health Sciences and Department of Microbiology. A response rate of $99.2 \%$ was obtained from the respondents. The most commonly used antibiotics were tetracycline and amoxicillin. Antibiotic use for common cold was observed in $32.3 \%$ of the respondents while $17.7 \%$ used antibiotics for sore throat. Majority of the participants $(72.4 \%)$ used the same antibiotics as previously prescribed by their doctors to treat their perceived infections while $51.2 \%$ kept left over antibiotics with the intention of future use. More than half $(55 \%)$ of the students stopped taking their antibiotics when they felt better or when the symptoms of their infections appeared to have stopped. The students' rating of their sources of antibiotics and prescription for antibiotics indicated that most of the students do not know the appropriate sources from where to purchase their antibiotics nor do they know the appropriate persons from whom to obtain a prescription for antibiotics.

The study showed a high rate of consumption of antibiotics among university undergraduates who mostly obtain their antibiotics without a physician's prescription from unofficial sources and do not complete their course of antibiotic therapy. These students need better education on the appropriate use of antibiotics in order to improve their attitude towards antibiotics.
\end{abstract}

\section{Key words}

Anti-bacterial agents and administration and dosage; Students; Data collection; Nigeria

\section{Corresponding Author}

Igbeneghu Oluwatoyin Abimbola

Department of Pharmaceutics, Obafemi Awolowo University, Ile-Ife, Nigeria.

Tel: 08056307805

Email: oaigbene@oauife.edu.ng 


\section{Introduction}

Antibiotics were discovered about eight decades ago and since then there has been a revolution in the management, treatment and outcome of infectious diseases. ${ }^{1}$ Antibiotics are therefore one of the most commonly prescribed, sold and used drugs worldwide. ${ }^{2}$ This use, which could be appropriate or inappropriate, has been viewed as a key driver for the emergence, increase and spread of antibiotic resistance. ${ }^{3}$ All antibiotic use, appropriate or not, has been described as "using up" some of the effectiveness of that antibiotic and so diminishing our ability to use it in the future. ${ }^{4}$

In many developing countries, antibiotics are available without prescription ${ }^{5-7}$ and so individuals use antibiotics indiscriminately. Antibiotics are used at wrong doses, for wrong indications, at wrong dosing intervals and for too long or inadequate length of time. ${ }^{5,7}$ The poor hygiene and sanitation in most developing countries also augments the spread of antibiotic resistant bacteria in vulnerable populations.

One of the key areas in the control of antibiotic resistance is a change in the behaviour of consumers and providers of antibiotics. ${ }^{1}$ Major resistance control strategies therefore recommend education of the public to promote appropriate antibiotic use..$^{8-9}$ The type and nature, as well as the extent of education to be given to the public, will depend on the kind of population to be addressed at any point in time. The kind of education needed by medical doctors and people with some knowledge of medical sciences will be different from that needed by individuals who do not have any background in the medical sciences. Also that of individuals with a formal education or basic education without a degree will be different from that of completely illiterate consumers of antibiotics. ${ }^{10}$

The aim of this study was therefore to examine the knowledge and practice of antibiotic use among students in a university in south western Nigeria so as to know the kind of education on antibiotics that would be applicable to them.

\section{Materials and methods}

A questionnaire was designed by reviewing relevant literatures and questionnaires previously used in similar studies. ${ }^{11-15}$ The questionnaires were pre-tested by administering them to 30 respondents who were not part of the sample population in order to determine the reliability of the questionnaire.

The questionnaire comprised of five sections. In the first section, respondents were asked questions on demographic characteristics which included the age, sex, religion, ethnicity, marital status, department and academic level, place of residence in school and place of residence when not in school. The second section had questions assessing the respondents' knowledge of infectious diseases while the third section assessed respondents' knowledge of antibiotics (the study assessed antibacterial and antifungal agents but not antiviral agents). The fourth and fifth sections had questions testing respondents' knowledge of the use of antibiotics and the storage and disposal of antibiotics respectively. Questions in the questionnaire comprised of some with yes/no options as well as preformed questions with options for respondents to select from by ticking with space provided for any other responses not included in options given.

Data obtained was analyzed using SPSS version 13.0, which uses the frequency as a tool in the analysis. In assessing the knowledge of the students on the proper source of antibiotics and prescription for antibiotics, they were provided with some official and unofficial sources of antibiotics and prescription for antibiotics. Each source was to be rated using any of the four point Likert Scale of Never, Rarely, Sometimes and Always. To arrive at an index, a weight value of 4, 3, 2 and 1 was attached to each of the above rating respectively. Students who get antibiotics or prescription from official sources were rated as follows: Always (4), Sometimes (3), Rarely (2) and Never (1) while those that get theirs from unofficial sources were rated as follows: Always (1), Sometimes (2), Rarely (3) and Never (4). The index is gotten by obtaining Summation of Weight Value (SWV). The SWV is obtained through the summation of the product of the number of responses for each rating to a source and the respective weight value. This is expressed mathematically as:

$$
\mathrm{SWV}=\sum_{i=1}^{5} X_{i} Y_{i}
$$


Where: SWV = Summation of weight value,

$X_{i}=$ number of respondents to rating $i$;

$Y_{i}=$ the weight assigned a value $(i=1,2,3,4)$.

$\mathrm{Al}=$ aggregate index, for the sources.

An aggregate index (Al) for each source is gotten by dividing the SWV by the summation of the respondents to each of the four ratings of a component expressed mathematically as:

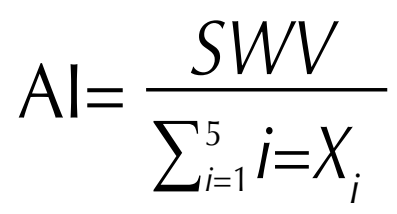

The mean Aggregate Index for the study area was computed.

For the purpose of this study, the following definitions applied to the sources of respondents' antibiotics: Street Peddlers are unofficial sellers of drugs of various kinds who mostly hawk the drugs openly in trays or wheelbarrows or hidden in suitcases; Traditional Healers are practitioners who specialize in the use of herbs and other materials of natural origin for healing. Some however incorporate antimicrobial agents into their products; Market includes stalls located within government-approved areas for sale of almost all kinds of household goods ranging from food items to clothing materials; Patent medicine vendors are outlets allowed to sell only over-the-counter (OTC) products, such as cough syrups, painkillers, and some antimalarial drugs. They are not permitted to stock prescriptiononly medicines but some do so illegally. Hospitals and Pharmacies are official sources of antibiotics to hospital out-patients and the community.

\section{Results}

Out of 500 questionnaires, 496 were returned properly filled giving a response rate of $99.2 \%$. The respondents were aged between 15 and 29 years with a mean of 18.6 years. The distribution of respondents based on their faculties is shown in figure 1 while table I shows the other demographic characteristics of the respondents.

The results of the study showed that $98 \%$ of the respondents have heard about micro-organisms while $96 \%$ of respondents claim to know what infections are. The infections known to the respondents included Cholera, dysentery, cough, sore throat, typhoid fever, and diarrhoea (Table II). Most of the respondents $(70.2 \%)$ have had infections at one time or the other

Table I. Demographic characteristics of respondents

\begin{tabular}{|c|c|c|}
\hline Characteristics & Frequency $(n=496)$ & Percentage \\
\hline \multicolumn{3}{|c|}{ Respondent's sex ( $p=0.7)$} \\
\hline Male & 237 & 47.8 \\
\hline Female & 259 & 52.2 \\
\hline \multicolumn{3}{|c|}{ Age group in years $(p<0.0001)$} \\
\hline Less than 18 & 74 & 14.9 \\
\hline $21-24$ & 293 & 59.1 \\
\hline 25 and above & 117 & 23.6 \\
\hline \multicolumn{3}{|c|}{ Religious belief $(p<0.0001)$} \\
\hline Christianity & 349 & 70.4 \\
\hline Islam & 143 & 28.8 \\
\hline Others & 4 & 0.8 \\
\hline \multicolumn{3}{|c|}{ Marital Status $(p<0.0001)$} \\
\hline Single & 460 & 92.7 \\
\hline Married & 31 & 6.2 \\
\hline
\end{tabular}




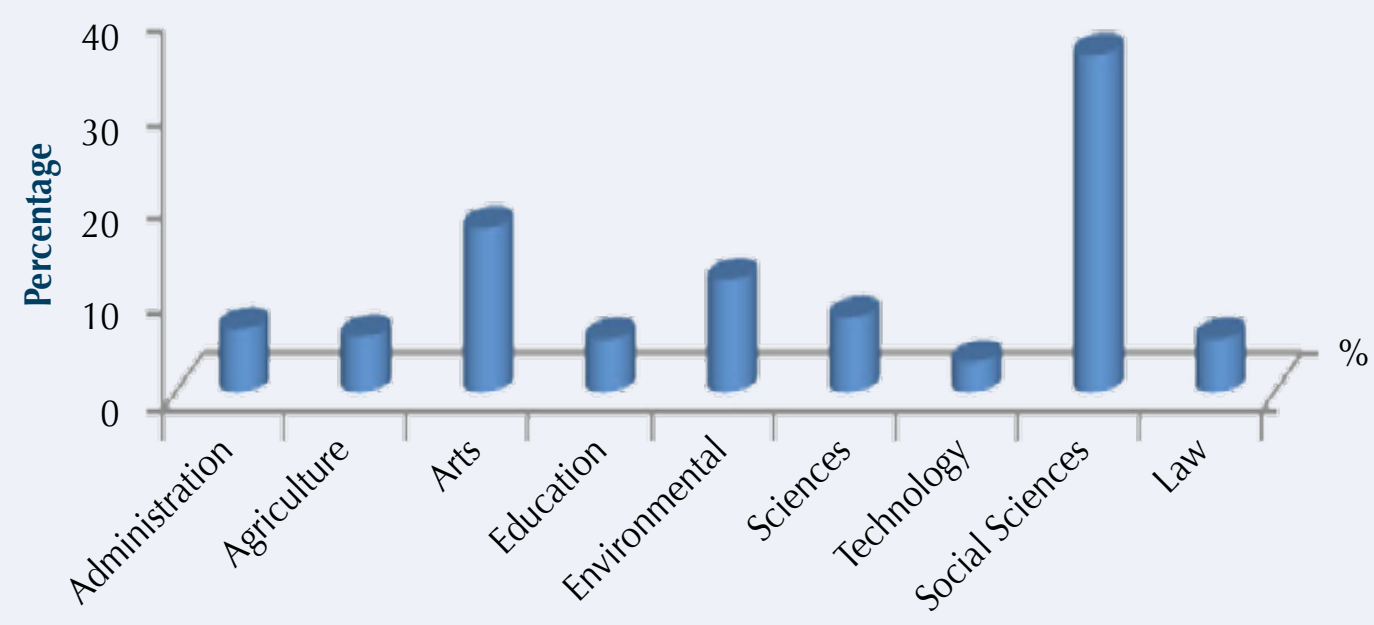

Faculties

Figure 1. Distribution of respondents from different faculties

Table II. Infections and perceived sources of infections

\begin{tabular}{lrr} 
Responses & Frequency & Percentage \\
\hline Infections known to respondents $(\mathbf{n = 4 9 6 )}$ & & \\
\hline Cholera & 55 & 11.1 \\
\hline Dysentery & 55 & 11.1 \\
\hline Cough & 136 & 27.9 \\
\hline Sore throat & 78 & 15.7 \\
\hline Typhoid fever & 50 & 10.1 \\
\hline Diarrhoea & 95 & 19.2 \\
\hline Perceived source of infections in respondents $(\mathbf{n}=\mathbf{3 4 8})$ & & \\
\hline Water & 154 & 44.3 \\
\hline Another Person & 116 & 33.3 \\
\hline Food & 106 & 30.5 \\
\hline Toilet & 92 & 26.4 \\
\hline Air & 2 & 0.6 \\
\hline Insect bites & 2 & 0.6 \\
\hline
\end{tabular}

while $29.8 \%$ claimed not to have contacted any infections before. Of the number of those that had been infected at one point or another, respondents thought they contacted the infection from water, food, toilets, other persons, and other sources which included air and insect bites (Table II).

Almost all the respondents $(91.4 \%)$ indicated that they have heard about antibiotics before while only
$83.1 \%$ stated that they had taken antibiotics before. The respondents' answers to questions on their reasons for using antibiotics showed that $32.3 \%$ and $17.7 \%$ of respondents used antibiotics for common cold and sore throat respectively (Table III). The most frequently used oral antibiotics in the group listed in the questionnaire (amoxicillin, amoxicillin+clavulanic acid, ampicillin+cloxacillin, ciprofloxacin, co-trimoxazole, erythromycin, fluconazole, metronidazole, nystatin, 
Table III. Respondents' reasons for taking antibiotics

\begin{tabular}{lrr} 
Condition & Frequency $(\mathbf{n}=\mathbf{4 1 2})$ & Percentage \\
\hline Common cold & 133 & 32.3 \\
\hline Diarrhoea & 89 & 21.6 \\
\hline Sore throat & 73 & 17.7 \\
\hline Typhoid fever & 60 & 14.6 \\
\hline Peptic Ulcer & 33 & 8 \\
\hline
\end{tabular}

and tetracycline) was tetracycline (35\%) followed by amoxicillin (33\%) while the least used was ciprofloxacin (12\%). Furthermore, the study revealed that a larger proportion of the respondents $(72.4 \%)$ use the same antibiotics as previously prescribed by their doctor to treated an infection. Unfinished antibiotics were thrown away by $20 \%$ of the respondents while $79.4 \%$ kept the antibiotics with $51.2 \%$ keeping left over antibiotics with the intention of use in a new infection. Left over antibiotics was kept in drawers, first aid boxes, baskets, and refrigerators by $36 \%, 22.4 \%$, $18.1 \%$, and $6.6 \%$ of the respondents respectively. Other places of storage of antibiotics mentioned by $17.1 \%$ of the respondents included hand bags, table tops and open shelves.

The computed mean Aggregate Index for the sources of respondents' antibiotics is shown in table IV while that computed for persons recommending the antibiotics is presented in table $\mathrm{V}$.

\section{Discussion}

The results of this study showed that respondents know that infections caused by microorganisms are transmitted via different routes with water, other individuals and food being the most known. Respondents also know that antibiotics are used to treat infections with a high rate of use found among the university undergraduates. The ß-lactam antibiotics (ampicillin + cloxacillin and amoxicillin) and tetracycline were the most commonly used antibiotics among the students. This observation is probably related to the high rate of resistances observed among enteric commensals from subjects in the study environment to the penicillins and tetracycline. ${ }^{16}$ The quinolones were the least used by the respondents and invariably a lower level of quinolone resistance was observed in the environment. ${ }^{16}$ This rate of use is similar to that reported among undergraduates in a university in Northern Nigeria. ${ }^{17}$

The use of antibiotics observed was not only high but also irrational. Irrational use included use of antibiotics for wrong indications, incomplete course of treatment and self medication. The reasons for use of antibiotics revealed that respondents do not know the difference

Table IV. Students' rating of their sources of antibiotics

\begin{tabular}{lrrrrrrr} 
Sources & Always & Sometimes & Rarely & Never & SWV & Al & Al- $\overline{A l}$ \\
\hline${ }^{*}$ Street Peddlers & 1 & 18 & 33 & 291 & 1300 & 3.79 & +0.18 \\
*Traditional Healers & 7 & 24 & 32 & 283 & 1283 & 3.71 & +0.10 \\
*Market & 15 & 41 & 53 & 241 & 1220 & 3.49 & -0.12 \\
**Pharmacy / chemist & 120 & 161 & 85 & 24 & 1157 & 2.97 & -0.64 \\
**Hospital & 82 & 177 & 79 & 41 & 1058 & 2.79 & -0.82 \\
*Patent medicine vendor & 7 & 51 & 67 & 225 & 1302 & 3.72 & +0.11 \\
\hline \hline
\end{tabular}

$\overline{\overline{A l}}=3.61 \quad$ **APPROPRIATE, ${ }^{*}$ INAPPROPRRATE 
Table V. Students' rating of persons recommending their antibiotics

\begin{tabular}{lrrrrrrr} 
Person & Always & Sometimes & Rarely & Never & SWV & Al & Al- $\overline{A l}$ \\
\hline *Physician & 102 & 176 & 89 & 36 & 1150 & 2.85 & -0.07 \\
*Pharmacist & 53 & 177 & 103 & 58 & 1007 & 2.58 & -0.34 \\
*Nurse & 52 & 142 & 96 & 84 & 960 & 2.57 & -0.33 \\
**Friend & 15 & 74 & 121 & 151 & 1130 & 3.13 & +0.21 \\
$* *$ Others & 10 & 33 & 46 & 185 & 954 & 3.48 & +0.56 \\
$\overline{A l}=\mathbf{2 . 9 2}$ & *Official, could recommend ${ }^{* *}$ unofficial, should not recommend & & &
\end{tabular}

between bacterial and viral infections and therefore use antibiotics for both kinds of infections. About a third of respondents use antibiotics for common cold. This observation has been reported by many studies conducted among university undergraduates and other individuals in the public. ${ }^{11,18-20}$ This lack of understanding of infectious diseases is a reason why many use antibiotics in the treatment of common cold. The treatment of diarrhoea in most cases does not need antibiotic therapy as mostacute diarrhoea is self-limiting except in invasive cases. ${ }^{21}$ In this study, more than a fifth of the respondents use antibiotics indiscriminately in the treatment of diarrhoea which may be dangerous as some cases of enteroheamorrhagic Escherichia coli infection have been associated with increased risk of the development of haemolytic uremic syndrome after indiscriminate antibiotic treatment. ${ }^{22-23}$

This study revealed that $72.4 \%$ of respondents use same antibiotics as previously prescribed by their doctor to treat their perceived infections. Self medication with antibiotics is defined as the acquisition and selfadministration of antibiotics with the aim of treating a perceived infection. ${ }^{24}$ This practice which has been observed in both industrialized and developing countries $^{24-25}$ is more common in the latter due to the poor socioeconomic status of the people and poor accessibility to barely available medical facilities. ${ }^{24,26-}$ ${ }^{28}$ Factor that could encourage self medication among university students have been identified as assumed knowledge of diseases and their treatments, prior experience on the use of antibiotics, lack of time to visit physicians and poor financial status. ${ }^{17,20}$

Incomplete course of antibiotic treatment was observed among the respondents in this study. More than a third of the respondents stop taking their antibiotics when they feel better or when symptoms of their infections appear to have stopped. This is a misconception in the use of antibiotics and those involved are at the risk of infection relapse, colonization with antibiotic resistant organisms and complicated disease outcomes. ${ }^{29-31}$ Sub-inhibitory concentrations of antibiotic in the body which results from incomplete dosage regimen may lead to the development of resistance by the pathogen causing the infection being treated. Similar studies in Pakistan and Jordan reported that $42 \%$ of Pakistani and $59 \%$ of Jordanian university students stop taking their antibiotics as soon as their symptoms disappear., ${ }^{6,20}$ This should be discouraged to reduce or delay the emergence and spread of antibiotic resistance in the community.

Most respondents (79.4\%) kept left-over antibiotics while $51.2 \%$ kept them with the intention of use in new infection(s). The storage or disposal of unused antibiotics by respondents could also encourage inappropriate antibiotic use. The practice of keeping left-over antibiotic inside drawers in most cases without locks increases its accessibility which increases the tendency for misuse not only by the person who stored it but also by others around. The possibility of the availability of left-over antibiotics around to encourage students with perceived infections to self medicate rather than consult physicians for diagnosis and treatment is also present. A similar study reported that about $88 \%$ of respondents keep left over antibiotics for personal future use or for friends and relatives. ${ }^{6}$ This has been described as injurious ${ }^{32}$ and therefore university undergraduates need to keep unused antibiotics out of the reach of others. Other ways of preventing or reducing this practice is for pharmacists to dispense 
exact number of doses in a single course of antibiotic treatment rather than whole drug pack and counselling patients on risks associated with incomplete course of antibiotic therapy.

The responses of the students on who recommends their antibiotics showed that persons recommending their antibiotics are usually non-competent persons. The ideal person, the physician, had Aggregate Index of 2.85 which was lower than the mean and the deviation from the mean was negative showing that respondents usually take antibiotics based on the recommendation of their friends and other persons other than a physician. The computed Aggregate Index for friends and other persons were 3.13 and 3.48 respectively which were higher than the mean and had positive deviations from their mean. The results also showed that the students have a poor knowledge of the right sources of antibiotic as they do not get their antibiotics from ideal sources. The first three ranked sources that students mentioned for purchasing their antibiotics were street peddlers, patent medicine vendors, and traditional healers. In essence, the students rarely visit ideal sources for antibiotics. Confirming this is the negative deviation of ideal sources such as pharmacy Shop (-0.64) and hospitals (-0.82) and their mean and respective aggregate indexes were lower than that of the study.

It is evident from the study that the students have a poor knowledge of the right source of antibiotics and from whom to obtain their prescriptions for antibiotics; they would therefore purchase their antibiotics from the wrong sources without a prescription. The ability to obtain antibiotics from some sources without a physician's prescription would encourage self medication and the continued patronage of such sources.

In conclusion, this study shows a high rate of consumption of antibiotics among university undergraduates who mostly obtain antibiotics without a physician's prescription from wrong sources and usually do not complete their course of antibiotic therapy and lack the understanding of the proper use and storage of antibiotics. These students need better education on the appropriate use of antibiotics in order to improve their attitude towards antibiotics and their use. The incorporation of compulsory elective courses on the proper use and misuse of antibiotics into course curriculums may be necessary. Furthermore, educational campaigns outside the classrooms and lecture rooms should be organized to address these issues. Finally, strict policies on the procurement and sale of antibiotics must be enforced by the appropriate authorities.

\section{Acknowledgement}

The author would like to thank the questionnaire respondents for the time spent in filling the questionnaires.

\section{References}

1. Cars $\mathrm{O}$, Högberg L, Murray $M$, et al. Meeting the challenge of antibiotic resistance. BMJ 2008; 337: a1438. http://dx.doi. org/10.1136/bmj.a1438

2. Buke AC, Ermertcan S, Hosgor-Limoncu M, Ciceklioglu M, Eren S. Rational antibiotic use and academic staff. Int I Antimicrob Agents 2003; 21: 63-66. http://dx.doi.org/10.1016/S09248579(02)00272-8

3. Nordberg P, Monnet DL, Cars O. Antibacterial drug resistance. [Background document] Priority medicines for Europe and the World "A Public Health Approach to Innovation". WHO, Geneva" 2004.

4. Laxminarayan R, Malani A, Howard D, Smith DL. Extending the cure: policy responses to the growing threat of antibiotic resistance. Alexandria: Resources for the Future, 2007. www. extendingthecure.org/research_and_downloads.html

5. Okeke NI, Lamikanra A, Edelman R. Socioeconomic and behavioral factors leading to acquired bacterial resistance to antibiotics in developing countries. Emerg Infect Dis 1999; 5: 18-27. http://dx.doi.org/10.3201/eid0501.990103

6. Arshad MS, Rasool MF, ljaz M, Hussain A. Evaluation of antibiotic use behavior in cold and flu amongst the students of Bahauddin Zakariya University Multan Pakistan. Pak J Pharm 2007-2010; 20-23 (1 \& 2): 15-22.

7. Nambatya J, Nyairo S, Bironse M, Kachwiya S, Musigunzi $\mathrm{N}$, Kamulegeya A. Antibiotic use knowledge and behavior at a Ugandan University. Int J Infect Control 2011; v7:i4. doi: 10.3396/ijic.V7i4.029.11. http://dx.doi.org/10.3396/ijic. V7i4.029.11

8. Finch RG, Metlay JP, Davey PG, Baker LJ. Educational interventions to improve antibiotic use in the community: report from the International Forum on Antibiotic Resistance (IFAR) colloquium. Lancet Infect Dis 2004; 4: 44-53. http:// dx.doi.org/10.1016/S1473-3099(03)00860-0

9. Ranji SR, Steinman MA, Shojania KG, Gonzales R. Interventions to reduce unnecessary antibiotic prescribing: a systematic review and quantitative analysis. Medical Care 2008; 46: 847-862. http://dx.doi.org/10.1097/MLR.0b013e318178eabd

10. Eng JV, Marcus R, Hadler JL, et al. Consumer attitudes and use of antibiotics. Emerg Infect Dis. 2003; 9: 1128-1135. http:// dx.doi.org/10.3201/eid0909.020591

11. Buke C, Hosgor-Limoncu M, Ermertcan $S$, et al. Irrational use of antibiotics among university students. I Infect 2005; 51: 135-139. http://dx.doi.org/10.1016/j.jinf.2004.12.001

12. Chen $\mathrm{C}$, Chen $\mathrm{YM}, \mathrm{Hwang} \mathrm{KL}$, et al. Behavior, attitudes and knowledge about antibiotic usage among residents of Changhua. Taiwan J Microbiol Immunol Infect 2005; 38: 5359. 
13. You JH, Yau B, Choi KC, Chau CTS, Huang QR, Lee SS. Adult knowledge, attitudes and behavior on antibiotic use: a telephone survey in Hong Kong. Infection 2008; 36: 153-157. http://dx.doi.org/10.1007/s15010-007-7214-5

14. McNulty CA, Boyle P, Nichols T, Clappison P, Davey P. Don't wear me out - the adult's knowledge of and attitudes to antibiotic use. I Antimicrob Chemother 2007; 59: 727-738. http://dx.doi.org/10.1093/jac/dkl558

15. McNulty CAM, Boyle P, Nichols T, Clappison P, Davey P. The public's attitudes to and compliance with antibiotics. J Antimicrob Chemother 2007; 60: 163-168. http://dx.doi. org/10.1093/jac/dkm161

16. Okeke I, Fayinka S, Lamikanra A. Antibiotic resistance in Escherichia coli from Nigerian students, 1986-1998. Emerg Infect Dis 2000; 6: 393-396.

17. Olayemi OJ, Olayinka BO, Musa Al. Evaluation of antibiotic self-medication pattern amongst undergraduate students of Ahmadu Bello University (main campus), Zaria. Research Journal of Applied Sciences Engineering and Technology 2010; 2(1): 35-38.

18. McKee MD, Mills L, Mainous AG. Antibiotic use for the treatment of upper respiratory infections in a diverse community. J Fam Pract 1999; 48: 993-996.

19. Grigoryan L, Burgerhof JG, Haaijer-Ruskamp FM, et al. Is selfmedication with antibiotics in Europe driven by prescribed use? J Antimicrob Chemother 2007; 59: 152-156. http://dx.doi. org/10.1093/jac/dkl457

20. Suaifan G, Shehadeh M, Darwish D, Al-ljel H, Yousef A, Darwish R. A cross-sectional study on knowledge, attitude and behavior related to antibiotic use and resistance among medical and non-medical university students in Jordan. African Journal of Pharmacy and Pharmacology 2012; 6(10): 763-770.

21. De Wit MA, Koopmans MP, Kortbeek LM, van Leeuwen NJ, Vinje J, van Duynhoven YT. Etiology of gastroenteritis in Sentinel general practices in the Netherlands. Clin Infect Dis 2001; 33: 280-288. http://dx.doi.org/10.1086/321875
22. Wong CS, Mooney JC, Brandt JR, et al. Risk Factors for the Hemolytic Uremic Syndrome in Children Infected With Escherichia coli O157:H7: A Multivariable Analysis. Clin Infect Dis 2012; 55(1): 33-41. doi:10.1093/cid/cis299. http://dx.doi. org/10.1093/cid/cis299

23. Smith KE, Wilker PR, Reiter PL, Hedican EB, Bender JB, Hedberg CW. Antibiotic treatment of Escherichia coli O157 infection and the risk of hemolytic uremic syndrome, Minnesota. Pediatr Infect Dis / 2012; 31(1): 37-41. http://dx.doi.org/10.1097/ INF.0b013e31823096a8

24. Awad A, Eltayeb I, Matowe L, Thalib L. Self-medication with antibiotics and antimalarials in the community of Khartoum State, Sudan. J Pharm Pharm Sci 2005; 8: 326-331.

25. Vaandnen $\mathbf{M H}$, Pietila K, Airaksinen M. Self-medication with antibiotics - does it really happen in Europe? Health Policy 2006; 77: 166-171. http://dx.doi.org/10.1016/j. healthpol.2005.07.001

26. Isturiz RE, Carbon C. Antibiotic use in developing countries. Infect Control Hosp Epidemiol 2007; 21: 394-397. http:// dx.doi.org/10.1086/501780

27. Ibekwe PC. Healthcare problems in developing countries. Med Pract Rev 2010; 1(1): 9-11.

28. Omotoso O. Location distribution of rural medical services for effective development: A case of Ekiti State, Nigeria. J Innov Res Manag Hum 2012; 1(1): 26-32.

29. Carey B, Cryan B. Antibiotic misuse in the community-a contributor to resistance? Ir Med J 2003; 96: 43-44.

30. Liu YC, Huang WK, Huang TS, Kunin CM. Inappropriate use of antibiotics and the risk for delayed admission and masked diagnosis of infectious diseases: a lesson from Taiwan. Arch Intern Med 2001; 161: 2366-2370. http://dx.doi.org/10.1001/ archinte.161.19.2366

31. Sarkar P, Gould IM. Antimicrobial agents are societal drugs: how should this influence prescribing. Drugs 2006; 66(7): 893-901. http://dx.doi.org/10.2165/00003495-20066607000001

32. Cliodna AM, McNulty C, Boyle P, Nichols T, Clappison $\mathrm{P}$, Davey P. The public's attitudes to and compliance with antibiotics. J Antimicrob Chemother 2007; 60(S1): i63-i68. 